\title{
A Correspondence Analysis of Seventeen Japanese Historical Third-Year English-as-a Foreign-Language Textbooks
}

\author{
Tomoo Asai, Ryohei Honda and Kiyomi Watanabe \\ Fukuyama Heisei University \\ Fukuyama, Japan \\ Toshiaki Ozasa \\ Hiroshima University (Professor Emeritus) \\ Higashi-Hiroshima, Japan
}

\begin{abstract}
The present paper aims to quantitatively analyze the features of seventeen Japanese historical English-as-a-Foreign-Language textbooks, Book 3, and their current counterpart, by using a correspondence analysis, focusing on their similarities / differences, and to compare the results with those of the correspondence analysis of the Book-1 textbooks of the same set used in the present study. Before further going on to the description or analysis of the rest of the dimensions specified so far, a tentative assessment of the two major dimensions was conducted so as to evaluate the basic strategy adopted in the present correspondence analysis, which brought about a conclusion that the eighteen textbooks were distributed in such a skewed way due to the strong influence of Seisoku-3 that it was extremely difficult to continue the interpretation. Based on this judgement, it was concluded that it is more productive to stop the present correspondence analysis of the eighteen textbooks and to restart anew with a correspondence analysis of seventeen variants, excluding Seisoku-3. The following were the obtained results of the correspondence analysis of the seventeen textbooks. First, the correspondence analysis results proved capable of differentiating the features of the sixteen historical textbooks and their current counterpart quantitatively, specifying their similarities and differences. In particular, the correspondence analysis map comprised of the two major dimensions specified indicated that both of the two dimensions, Dim 1 (difficult vs. easy texts) and Dim 2 (natural-sounding vs. artificialsounding discourse) contributed to differentiating their interrelationships. Second, the explaining categories (dimensions, axes) proved to be explained 83.1 percent by seven dimensions, i.e., difficult vs. easy texts (Dim 1), natural-sounding vs. artificial-sounding discourse (Dim 2), dialogue-based vs. passage-based texts (Dim 3), teacher dominance vs. no teacher dominance (Dim 4), strictly controlled vs.
\end{abstract}


loosely controlled texts (Dim 5), redundant vs. concise texts (Dim 6) and connected vs. disconnected contents (Dim 7). Third, the similarities / differences of the seventeen Book-3 textbooks were explained by the same categories of the Book-1 result up to the seventh dimension. There were, however, small modifications had to be made on Dim3 and Dim 6, where the location of (positive, negative) poles were reversed. Finally, the results of the present Correspondence Analysis(CA) were graphically represented by two methods, (1) two-dimensional coordinate representation covering only two major dimensions, Dim 1 and Dim 2, and (2) cluster-analysis-based dendrogram covering all the features of sixteen dimensions. These representation revealed that on the two-dimensional coordinate representation, only two textbooks, Sunshine-3 and Inoue-p3, were separated as distinctively different from the other fifteen textbooks in terms of the two features, i.e., difficulty / easiness (Dim 1) and naturalness / artificialness (Dim 2), while on the dendrogram covering all of the sixteen features or categories specified, three textbooks, Inoue-p3, Sunshine-3 and Mombusho-p3 were separated as distinctively different from the others. These facts could suggest that all categories considered, two textbooks, Inoue-p3 and Mombusho-p3 should be included in the forerunner group represented by the current textbook, Sunshine-3.

Keywords: Correspondence analysis; English as a foreign language; Textbooks.

\section{Introduction}

It is to be noted first of all that the qualitative and quantitative analysis of Japanese historical English-as-a-foreign-language (henceforth EFL) textbooks is a narrow, limited area with very few researchers participating in developing and accumulating academic expertise in this field. This is probably because the research itself necessarily takes a time-consuming and energy-consuming process, which has to start with collecting relevant data scattered around and digitizing the collected historical data for quantitative analysis, transforming their graphic texts into textual corpora. (Honda, et al., 2018, Honda, Watanabe \& Ozasa, 2017)

To the best of the present writers' knowledge, Ozasa and Nakamura (2001) was the first academic contribution to the qualitative analysis of Japanese historical EFL textbooks in Japan, which, after presenting a bibliographical introduction of eight sets of Japanese historical EFL textbooks, depicted the subjects and contents of the eight sets based on a close reading of their texts. Ozasa (2003), reported the results of the quantitative analyses of six historical EFL textbooks published from 1883 to 1932, conducted using two readability measuring tools, Flesch Reading Ease and Flesch-Kincaid Grade Level, widely known and globally used readability tools.

Ozasa and Erikawa (Eds.) (2004) was a more comprehensive diachronic analysis of Japanese historical EFL textbooks, both qualitative and quantitative. In this study, sixteen sets of historical textbooks were described and qualitatively analyzed, covering most of the representative ones, and nine sets of textbooks 
were quantitatively analyzed in terms of lexical, grammatical and readability measures. The readability tools used in this analysis were also Flesch Reading Ease and Flesch-Kincaid Grade Level. Ozasa (2005) reported the quantitative diachronic analyses of fourteen historical EFL textbooks published from 1861 to 1939, with two post-WW2 textbooks, New Jack and Betty (1952) and Sunshine English Course (1996) for comparison, conducted using two readability measuring tools, Flesch Reading Ease and Flesch-Kincaid Grade Level.

In 2007, various kinds of techniques were employed in the synchronic and diachronic analysis of EFL corpora. Nakamura and Ozasa (2007) analyzed two kinds of corpora, (1) fourteen EFL textbooks used in Japan across a span of 135 years and (2) five Asian EFL textbooks, in terms of gender awareness, the results of which contributed to proving that the authors of EFL textbooks in Japan, except for those aiming at women's education, seemed to have lacked gender awareness. Weir and Ozasa (2007) measured the naturalness of the discourse of three Japanese historical EFL textbooks as denoted by their appropriateness to the parts-of-speech profile represented by the American English Brown corpus, the results of which suggested that all of the three textbook sets might be regarded as attaining a dimension of English naturalness.

Further, in this context, Weir and Ozasa (Eds.) (2007) and Weir and Ozasa (Eds.) (2008) compiled various kinds of synchronic and diachronic textbook studies using the techniques of corpus analysis, covering the areas of grammar, vocabulary, lexical collocation, semantics, readability, language acquisition, among others. Specifically, Ozasa, Umamoto, Matsuoka, and Motooka (2008) reported on the diachronic comparison of the first-year books of twenty-three historical EFL textbooks with their current counterpart for comparison, focusing on their overall tokens, types and new types, finding that older textbooks were generally higher than newer ones in the token / new type ratio. Matsuoka, Umamoto, Ozasa, and Motooka (2008) reported on the diachronic comparison of the same set of EFL textbooks, focusing on the frequency of the past and the present forms of $b e$-verbs and general verbs, finding that some textbooks in the Meiji Era (1868-1912), especially Seisoku (1889) and Drill (1907), laid the foundation of the grammar control in the Taisho (1915-1926) and Showa Era (1926-1989).

Also, Hosaka and his team reported a quantitative comparison of seven Japanese historical EFL textbooks, focusing on the occurrences of to-infinitive forms and of verbal forms. Hosaka, Abe, Uenishi, and Ozasa (2008), based on the findings of the diachronic comparison of to-infinitive, concluded that students mastered the three types of to-infinitive usage (noun, adverb and adjective usage) in the first grade before WW2, then started learning and mastering them in the second grade, while in the currently used textbooks, they are required to master the adjective usage in the third grade. Hosaka, Erikawa, Miura, and Ranjan (2008), based on the results of the diachronic comparison of verbal usage, proposed a hypothesis that H. E. Palmer, British applied linguist invited to Japan by the Japanese Government, was the first person to intentionally compile a grammarbased textbook in middle school in Japan. 
George R. S. Weir, specialist in computer science and computer programming as well as in philosophy, put his high-tech expertise into practical use in the quantitative analysis of Japanese EFL textbook corpora. Weir and Ozasa (2008) computed and compared the frequency of individual words and multiword sequences (n-grams) across three Japanese historical EFL textbook corpora, the results of which revealed that Jack and Betty, a post-WW2 textbook, diverged more from the other two pre-WW2 textbook series in terms of n-gram frequencies. Weir and Ozasa (2009) performed a test of the assumption that the three sets of the above Japanese historical EFL textbooks exhibit priority of grammatical over vocabulary consideration, and found that there were discernible trends in verb usage which were strong evidence of grammar control across books in each textbook series. Weir and Ozasa (2010) also reported on the application of computer-based text analysis tools, i.e., n-gram frequency, hapax legomena and Dolch word, in the diachronic quantitative comparison of the above three Japanese EFL textbook corpora, and suggested that their hypothesis that grammar control was prominent in the textbooks' design might be further explored by using other analysis tools like Posit.

In 2016, a new attempt was made in the quantitative diachronic analysis of Japanese EFL textbook corpora in Kawamura, Umamoto, and Ozasa (2016), which was further followed by Kawamura, Umamoto, Matsuoka, and Ozasa (2017). In these, using the same textbook corpora as those of Ozasa and Erikawa (Eds.) (2004), new quantitative analyses were carried out by using a newly developed readability measuring tool attuned to the new Japanese EFL standard set up in the revised English course of study, i.e., Ozasa-Fukui Year Level, Ver. 3.4.2nhnc1-5 $\left(\mathrm{r}^{\wedge} 2=0.8802\right)$ (Ozasa, Fukui, \& Watanabe, 2015) and Ver. 3.5nhnc1-6 $\left(\mathrm{r}^{\wedge} 2=0.8912\right)$ (Ozasa, Watanabe, \& Fukui, 2016). The former study, based on a diachronic analysis of eight sets of Japanese historical EFL textbooks and their current counterpart in terms of readability, specified the readability levels of the nine sets and clustered them into three groups based on their measurement results. The latter, based on the same approach with four sets, two Japanese middle school EFL textbooks for girls and two for boys, measured their readability, finding that the textbooks for girls were easier than the ones for boys in readability.

These studies were also followed by five new attempts using CA in 2017 and 2018; (1) Sakamoto, Watanabe, and Ozasa (2017), (2) Watanabe, Asai, and Ozasa (2017), (3) Honda, Watanabe, and Ozasa (2017), (4) Ozasa, Kawamura, Umamoto, and Matsuoka (2018) and (5) Honda, Asai, Watanabe and Ozasa (2018). To the best of the present writers' knowledge, the quantitative diachronic analyses of Japanese historical EFL textbook corpora using CA started in Japan with Sakamoto, Watanabe, and Ozasa (2017), which computed a CA using five Japanese historical EFL textbooks and their current counterpart, proving $\mathrm{CA}$ to be powerful enough to quantitatively analyze, interpret and clarify the characteristic features, similarities and differences among the six textbooks. Watanabe, Asai, and Ozasa (2017) also performed the same type of CA, using five different Japanese historical EFL textbooks and two of their current counterparts, the results of which also proved that CA was able to 
quantitatively analyze, interpret and clarify the characteristic features, similarities and differences among the seven textbooks.

In Honda et al. (2017), the same type of CA-based diachronic quantitative analysis was carried out using nine Japanese historical EFL textbooks and their current counterpart, the results of which proved that CA was able to clarify the characteristic features, similarities and differences among the ten textbooks, specifying five criteria or dimensions. These findings were summarized by a nine-dimension-based dendrogram as well as a two-major-dimension-based coordinate representation. In Ozasa et al., (2018), a CA was computed using four Japanese historical EFL textbooks and their current counterpart, with the same aim as in the above analyses. The results of the analysis revealed that the five textbooks were explained by four criteria or dimensions, and these findings were graphically displayed by a four-dimension-based radar gram as well as a two-major-dimension-based coordinate representation.

Finally, in Honda, et al. (2018), the same type of quantitative diachronic analysis was computed using a relatively large number of variants (18 variants in this case), the results of which proved capable of differentiating the features of the seventeen historical textbooks and their current counterpart quantitatively, specifying their similarities and differences. In particular, the CA map comprised of the two major dimensions specified indicated that both of the two dimensions, Dim 1 (difficult vs. easy texts) and Dim 2 (natural-sounding vs. artificial-sounding discourse) contributed to differentiating their interrelationships clearly. It has to be noted that these findings were graphically summarized by a seventeen-dimension-based dendrogram as well as by a twomajor-dimension-based coordinate representation.

It is worthy of note that the results of all of these CA-based studies proved that the new statistic tool, was powerful enough to specify the distinctive features of textual corpora and to classify the EFL textbooks analyzed based on the specified distinctive features. In particular, in Honda et al. (2017) and Honda et al. (2018), CA proved capable of discriminating a relatively large number of variants and classifying Japanese historical EFL textbooks based on the distinctive features specified by the CA.

The present study, motivated by the same awareness and goals as in the preceding ones, especially by those of Honda et al. (2018), aims to quantitatively analyze and classify a relatively large number of historical EFL textbooks, seventeen textbooks and their current counterpart, from a new perspective, using a $\mathrm{CA}$ technique.

\section{Aim}

The present paper aims to quantitatively describe and explain the features of seventeen Japanese historical third-year EFL textbooks and their current counterpart, by using CA, focusing on their similarities / differences and to compare the results with those of the CA of the first year textbooks of the same set as the present one. CA is primarily a multivariate descriptive method of analysis that presents the relations between rows and columns in a frequency 
table graphically as points in a common low-dimensional space (Clausen, 1998, p. 1). It is a translation of the French "analyse de scorrespondances," but is also referred to by other names such as "dual scaling," "additive scoring," "optimal scaling," "biplot," and "homogeneity analysis" (Clausen, 1998, p. 50). Its main purpose is to reveal the structure of a complex data matrix (in the present analysis, a complex data matrix of the eighteen Japanese third-year EFL textbooks) by replacing the raw data with a more simple data matrix without losing essential information (Clausen, 1998, p. 1).

The following are the research questions (RQs) of the present study:

(1) How similar / different in contents are the seventeen Japanese historical EFL textbooks (Book 3) and their current counterpart to / from each other?

(2) What kinds of dimensions explain the similarities / differences among the eighteen textbooks?

(3) How similar / different in contents are the eighteen Japanese historical EFL textbooks (Book 3) to / from their first-year counterpart?

The textbooks used in the present CA were seventeen historical EFL textbooks published during the period from 1861 to 1952, and a currently used EFL textbook, which was included in the present analysis for comparative purposes. The following are the titles and bibliographical data of the eighteen textbooks, which is primarily based on Ozasa and Erikawa (Eds.) (2004). (As for the authors and characteristic features of these textbooks, please refer to Ozasa and Erikawa (Eds.) (2004) and Honda, et al. (2018).)

(1) Standard Choice Readers, 3 (Shobido Editorial, 1902, Shobido, 5 Vols.) (Henceforth Choice-3.)

(2) English Readers: The High School Series, 3 (Education Department, Japan [W. Dening], 1887-88, Education Department Publishing, Japan, 6 Vols.) (Henceforth Dening-3.)

(3) New English Drill Books, 3 (Kenjiro Kumamoto, 1907, Kaiseikan, 5 Vols.) (Henceforth Drill-3.)

(4) The Globe Readers, 3 (Yoshisaburo Okakura, 1907, Dainippon Tosho, 5 Vols.) (Henceforth Globe-3.)

(5) Shogakko Eigo Shin Tokuhon, 3 [New Primary School English Readers, 3] (Jukkichi Inoue, 1902, Kinkodo, 4 Vols.) (Henceforth Inoue-p3.)

(6) New Jack and Betty: English Step by Step, 3 (K. Hagiwara, M. Inamura \& K. Takezawa, 1951, Kairyudo, 3 Vols.) (Henceforth Jack\&Betty-3.)

(7) Shogakko Eigo Tokuhon, 3 [Primary School English Readers, 3] (Naibu Kanda, 1901, Sanseido, 4 Vols.) (Henceforth Kanda-p3.)

(8) Kanda's New Series of English Readers (Revised Edition), 3 (Naibu Kanda, 1905, Sanseido, 5 Vols.) (Henceforth Kanda-3.)

(9) Shogakko Yo Mombusho Eigo Tokuhon, 3 [Mombusho English Readers for Primary Schools, 3] (English Department [ed.], 1908-10, Joint Sales Agency for National Textbooks, 3 Vols.) (Henceforth Mombusho-p3.)

(10) New National Readers, 3 (C. J. Barnes, 1883-84, A. S. Barnes \& Co., 5 Vols.) (Henceforth National-3.)

(11) Girls' Pacific Readers, 3 (Torajiro Sawamura, 1939, Kairyudo, 5 Vol.) (Henceforth Pacific-3.) 
(12) Seisoku Mombusho Eigo Tokuhon, 3 [Education Department English Reader, A Regular Way, 3] (Education Department, Japan, 1889-90, Education Department Publishing, Japan, 5 Vols.) (Henceforth Seisoku-3.)

(13) The Standard English Readers, 3 (H. E. Palmer, 1927, Institute for Research in English Teaching, Japan, 5 Vols.) (Henceforth Standard(p)-3.)

(14) The Standard English Readers, 3 (Tsuneta Takehara, 1932, Taishukan, 5 Vols.) (Henceforth Standard(t)-3.)

(15) Girls' New Taisho Readers, 3 (Umeko Tsuda \& Kenjiro Kumamoto, 1916, Tokyo Kaiseikan, 4 Vols.) (Henceforth Taisho-3.)

(16) Tsuda English Readers, 3 (Joshi Eigaku Juku [English College for Women], 1931, Sanseido, 4 Vols.) (Henceforth Tsuda-p3.)

(17) Sanders' Union Readers, 3 (Charles Walton Sanders, 1861-67, Ivison, Blakeman, Taylor \& Co., 5 Vols.) (Henceforth Union-3.)

(18) Sunshine English Course, 3 (M. Niizato, Y. Sato, T. Yamaoka \& Y. Takanashi, 2012, Kairyudo, 3 Vols.) (Henceforth Sunshine-3.)

Through this analysis, we hope to quantitatively clarify the similarities / differences and relationships among the seventeen Japanese historical third-year EFL textbooks and their current counterpart and also the similarities / differences and relationships between the third-year books and the first-year books.

\section{Method}

The present study employed a one-way CA model with eighteen nominal variants, in order to explore the relationships among the eighteen Japanese third-year EFL textbooks, including a currently used junior-high school EFL textbook and to compare the results with those of the CA of the first year textbooks of the same set as the present one.

First, a cross-textbook tabulation table of the above-mentioned eighteen textbooks was prepared as a basic datum for the present CA, using the eighteen textbook corpora. This is practically a cross-textbook word-frequency table, which was made using $A n t C o n c$, a vocabulary processing tool. In this frequency table the most frequent 100 words (only content words and function words counted) were picked up from the frequency list and their frequency values were placed for each of the textbooks. (Since the eighteen kinds of 100-word frequency lists were incorporated into one cross-textbook frequency word table, the number of words of the cross tabulation table was more than 100.)

Then, using the digital datum of the cross tabulation table, a CA was carried out by using Fukui's College Analysis, a statistics computer program developed for social science research by Masayasu Fukui, professor of applied mathematics at Fukuyama Heisei University, Japan. In evaluating and interpreting the results of the analysis, some of the ideas and techniques developed in Tono (2000), Clausen (1998) and Fukui and Watanabe (2019) were used for reference where they were deemed relevant and appropriate to the analysis in the present paper. 


\section{Results and Discussion}

The present section is comprised of two subsections, i.e., (1) the description of the results of the CA with eighteen Japanese historical EFL textbooks and (2) the description of the CA with seventeen Japanese historical EFL textbooks.

\section{1. CA of 18 Variants}

Table 1 shows the basic statistics of the present CA, i.e., the eigenvalues, coefficient correlations, contribution rates and cumulative contribution rates of the analysis. As the contribution rate indicates in Table 1, the distinctive features of the eighteen nominal variants (textbooks) were explained $47.8 \%$ by the first dimension, $14.8 \%$ by the second dimension, $8.5 \%$ by the third dimension, $5.4 \%$ by the fourth dimension, $4.6 \%$ by the fifth dimension and $4.2 \%$ by the sixth dimension, the cumulative contribution rate being $85.3 \%$ on the sixth dimension. This means that six dimensions should be sufficient enough for the analysis and interpretation of the present results.

Table 1: Basic CA Data, 18 Textbooks (Book 3)

\begin{tabular}{|c|c|c|c|c|c|c|}
\hline & $\operatorname{Dim} 1$ & $\operatorname{Dim} 2$ & Dim 3 & $\operatorname{Dim} 4$ & Dim 5 & $\operatorname{Dim} 6$ \\
\hline Eigenvalue & 0.104 & 0.032 & 0.018 & 0.012 & 0.01 & 0.009 \\
\hline Correlation & 0.322 & 0.179 & 0.136 & 0.109 & 0.1 & 0.095 \\
\hline Contribution rate & 0.478 & 0.148 & 0.085 & 0.054 & 0.046 & 0.042 \\
\hline \multirow[t]{2}{*}{$\begin{array}{l}\text { Cumulative } \\
\text { contribution rate }\end{array}$} & 0.478 & 0.626 & 0.711 & 0.765 & 0.811 & 0.853 \\
\hline & Dim 7 & Dim 8 & Dim 9 & $\operatorname{Dim} 10$ & $\operatorname{Dim} 11$ & $\operatorname{Dim} 12$ \\
\hline Eigenvalue & 0.007 & 0.006 & 0.004 & 0.003 & 0.003 & 0.002 \\
\hline Correlation & 0.082 & 0.079 & 0.066 & 0.058 & 0.053 & 0.047 \\
\hline Contribution rate & 0.031 & 0.029 & 0.02 & 0.015 & 0.013 & 0.01 \\
\hline \multirow[t]{2}{*}{$\begin{array}{l}\text { Cumulative } \\
\text { contribution rate }\end{array}$} & 0.884 & 0.913 & 0.933 & 0.948 & 0.961 & 0.971 \\
\hline & $\operatorname{Dim} 13$ & $\operatorname{Dim} 14$ & $\operatorname{Dim} 15$ & $\operatorname{Dim} 16$ & Dim 17 & \\
\hline Eigenvalue & 0.002 & 0.002 & 0.001 & 0.001 & 0.001 & \\
\hline Correlation & 0.044 & 0.04 & 0.033 & 0.031 & 0.026 & \\
\hline Contribution rate & 0.009 & 0.007 & 0.005 & 0.004 & 0.003 & \\
\hline $\begin{array}{l}\text { Cumulative } \\
\text { contribution rate }\end{array}$ & 0.98 & 0.988 & 0.993 & 0.997 & 1 & \\
\hline
\end{tabular}

In order to evaluate the basic strategy adopted in the present CA, a tentative analysis and assessment of Dim 1 and Dim 2 only was performed before going through the holistic analysis of the results (Table 2, Table 3 and Figure 1). Table 2 shows the values of the eighteen textbook variants on Dim 1 as a description of the relationships among the eighteen variants on Dim 1. As it is clear in Table 2, on the first dimension, the value was the highest for Seisoku-3 (3.92), the second highest for Union-3 (-0.153) and the third highest for Dening-3 (-0.161), while it is the lowest for Mombusho-p3 (--0.441), the second lowest for Sunshine-3 (-0.323) and the third lowest for Inoue-p3 (-0.315). In decreasing order, the eighteen textbooks were: Seisoku-3 > Union-3 > Dening-3 > Taisho-3 > Kanda-3 > National-3 $>$ Kanda-p3 $>$ JackEBetty-3 $>$ Tsuda-p3 $>$ Choice-3 $>$ Drill-3 $>$ Standard(p)-3 $>$ Globe$3>$ Pacific-3 > Standard ( $t)-3>$ Inoue-p3 $>$ Sunshine-3 $>$ Mombusho-p3. The locations of these textbook variants were represented horizontally on the $x$ axis in Figure 1. 
It is interesting to note with this table that the distribution of the eighteen textbook variants are rather skewed, presumably influenced by the variant of Seisoku-3, the value of which is extremely high, almost reaching four point (3.93), while all of the other seventeen variants, presumably affected by Seisoku-3, are located in the minus value area. It could be concluded that this distribution (1 plus-value variant vs. 17 minus-value variants) is not normal but extremely on the skew under the influence of Seisoku-3.

Table 2: Values on Dim1

\begin{tabular}{|l|r|}
\hline & \multicolumn{1}{|c|}{ Dim 1 } \\
\hline Seisoku-3 & -9.153 \\
\hline Union-3 & -0.161 \\
\hline Dening-3 & -0.174 \\
\hline Taisho-3 & -0.191 \\
\hline Kanda-3 & -0.209 \\
\hline National-3 & -0.222 \\
\hline Kanda-p3 & -0.228 \\
\hline Jack\&Betty-3 & -0.229 \\
\hline Tsuda-p3 & -0.236 \\
\hline Choice-3 & -0.269 \\
\hline Drill-3 & -0.28 \\
\hline Standard(p)-3 & -0.284 \\
\hline Globe-3 & -0.297 \\
\hline Pacific-3 & -0.309 \\
\hline Standard(t)-3 & -0.315 \\
\hline Inoue-p3 & -0.323 \\
\hline Sunshine-3 & -0.441 \\
\hline Mombusho-p3 &
\end{tabular}

Table 3: Values on Dim 2

\begin{tabular}{|l|r|}
\hline & \multicolumn{1}{|c|}{ Dim 2 } \\
\hline Mombusho-p3 & 3.15 \\
\hline Inoue-p3 & 1.511 \\
\hline Sunshine-3 & 0.623 \\
\hline Pacific-3 & 0.484 \\
\hline Jack\&Betty-3 & 0.365 \\
\hline Seisoku-3 & 0.209 \\
\hline Tsuda-p3 & -0.024 \\
\hline Taisho-3 & -0.129 \\
\hline National-3 & -0.257 \\
\hline Standard(p)-3 & -0.332 \\
\hline Kanda-3 & -0.338 \\
\hline Standard(t)-3 & -0.582 \\
\hline Choice-3 & -0.603 \\
\hline Globe-3 & -0.606 \\
\hline Drill-3 & -0.651 \\
\hline Union-3 & -0.696 \\
\hline Kanda-p3 & -0.874 \\
\hline Dening-3 & -1.327 \\
\hline
\end{tabular}


Table 3 shows the values of the eighteen textbook variants on Dim 2 as a description of the relationships among the eighteen variants on Dim 2, and Figure 1 presents a graphic representation of the results. As it is clear in Table 3, on the second dimension, the value is the highest for Mombusho-p3 (3.15), the second highest for Inoue-p3 (1.511) and the third highest for Sunshine-3 (0.623), while it is the lowest for Dening-3 (-1.327), the second lowest for Kanda-p3 ($0.874)$ and the third lowest for Union-3 (-0.696). In decreasing order, the eighteen textbooks were: Mombusho-p3 > Inoue-p3 > Sunshine-3 > Pacific-3 > JackEBetty-3 > Seisoku-3 $>$ Tsuda-p3 $>$ Taisho-3 $>$ National-3 $>$ Standard( $p)-3>$ Kanda-3 $>$ Standard $(t)-3>$ Choice-3 $>$ Globe-3 $>$ Drill-3 $>$ Union-3 $>$ Kanda-p3 $>$ Dening-3. The locations of these textbook variants were represented vertically on the $y$ axis in Figure 1.

As a summary of the above descriptions and discussions, the CA map in Figure 1 visualizes the $62.6 \%$ of the spatial relationships among the eighteen nominal variants in focus, in which the $x$-axis represents the first dimension and the $y$ axis the second dimension. As it is clear in the two-dimensional coordinate representation in Figure 1, the vertical locations of the eighteen variants were clustered around one large group on the $y$-axis except for Mombusho-p3 and Inoue-p3. This means that there were very few differences discriminated or ascertained on the $y$-axis in this analysis with eighteen variants. Since the primary objectives of the present $\mathrm{CA}$ are to find out clear-cut criteria for classifying these historical EFL textbooks and to discriminate them in terms of the thus specified criteria, it seems to be extremely difficult to achieve these goals of the present study.

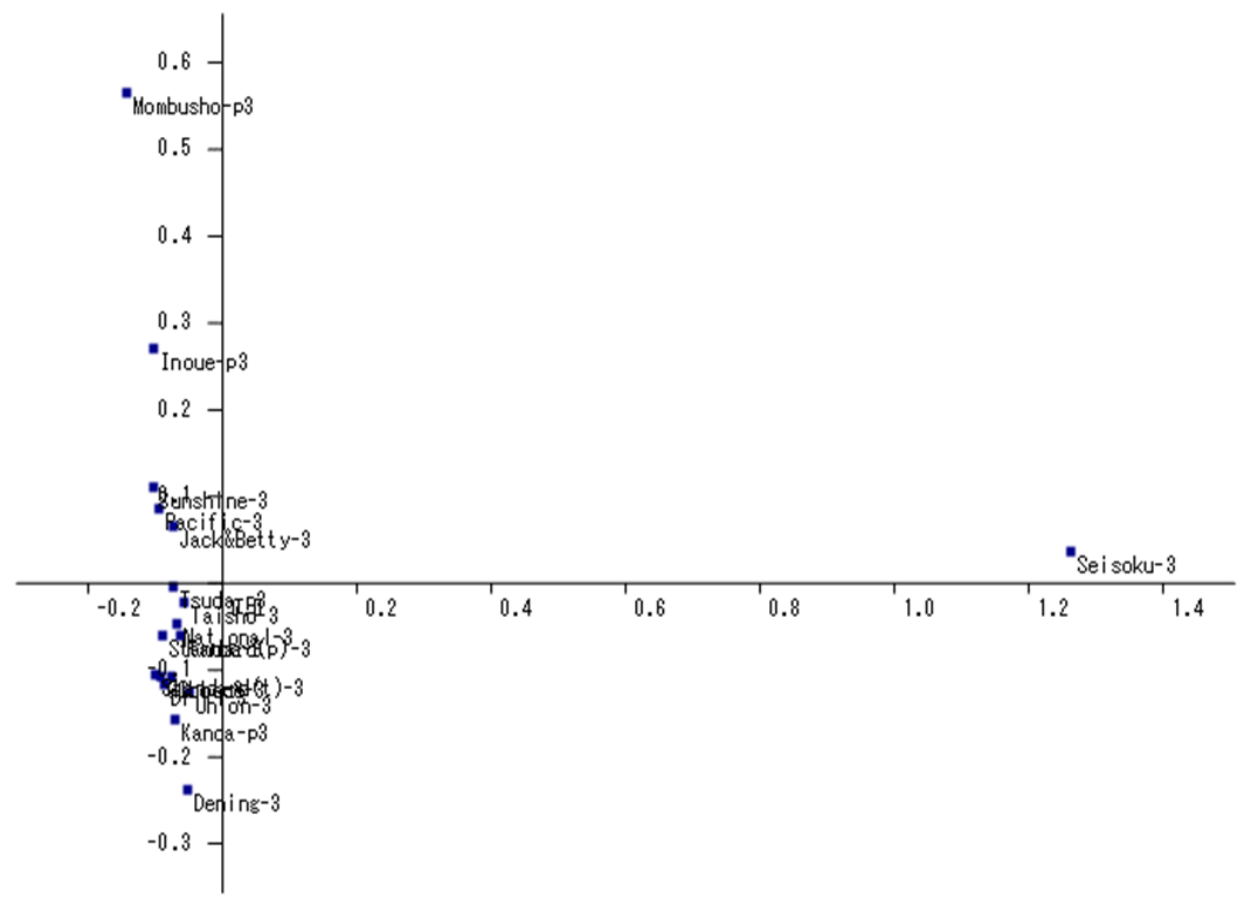

X-axis: $\operatorname{Dim} 1 \quad y$-axis: $\operatorname{Dim} 2$

Figure 1: 2-Dimentional CA Map of 18 Textbooks 
Before further going on to the description or analysis of the rest of the dimensions specified so far, a tentative assessment of the two major dimensions was conducted so as to assess the basic strategy adopted in the present CA. As a summary of the above two major dimensions, Figure 1 visualizes the location of the eighteen textbook variants on the two major dimensions, Dim 1 and Dim 2, and the $62.6 \%$ of their spatial relationships specified, in which the $x$-axis represents the first dimension and the $y$-axis the second dimension. As it is clearly shown in Figure 1, except for Seisoku-3, Mombusho-p3, Inoue-p3 and Dening-3, most of the textbooks, gathered in one large group, cannot clearly be discriminated from each other. In other words, the identity of these individual textbooks and their interrelationships were not clearly described in this analysis. This skewed distribution of the eighteen textbooks was presumably brought about by the strong influence of the characteristic features or particularities of Seisoku-3, which seems to be peculiarly different in contents from the other seventeen textbooks. Based on the results of this pre-analysis, the present writers have reached the conclusion that it is more productive to stop the present CA of the eighteen textbooks and to restart anew with a CA of seventeen variants, excluding Seisoku-3, which made a contribution to a rather skewed distribution of the eighteen variants both on Dim 1 and Dim 2.

\section{2. CA of 17 Variants}

Table 4: Basic CA Data, 17 Textbooks (Book 3)

\begin{tabular}{|c|c|c|c|c|c|c|}
\hline & $\operatorname{Dim} 1$ & $\operatorname{Dim} 2$ & $\operatorname{Dim} 3$ & $\operatorname{Dim} 4$ & $\operatorname{Dim} 5$ & $\operatorname{Dim} 6$ \\
\hline Eigenvalue & 0.035 & 0.02 & 0.013 & 0.011 & 0.01 & 0.007 \\
\hline Correlation & 0.187 & 0.141 & 0.112 & 0.106 & 0.097 & 0.086 \\
\hline Contribution rate & 0.284 & 0.163 & 0.102 & 0.091 & 0.077 & 0.06 \\
\hline \multirow[t]{2}{*}{$\begin{array}{l}\text { Cumulative } \\
\text { contribution rate }\end{array}$} & 0.284 & 0.446 & 0.548 & 0.639 & 0.716 & 0.777 \\
\hline & $\operatorname{Dim} 7$ & $\operatorname{Dim} 8$ & $\operatorname{Dim} 9$ & $\operatorname{Dim} 10$ & Dim 11 & $\operatorname{Dim} 12$ \\
\hline Eigenvalue & 0.007 & 0.005 & 0.004 & 0.003 & 0.003 & 0.002 \\
\hline Correlation & 0.082 & 0.069 & 0.062 & 0.055 & 0.05 & 0.046 \\
\hline Contribution rate & 0.054 & 0.039 & 0.031 & 0.024 & 0.02 & 0.017 \\
\hline \multirow[t]{2}{*}{$\begin{array}{l}\text { Cumulative } \\
\text { contribution rate }\end{array}$} & 0.831 & 0.87 & 0.9 & 0.925 & 0.945 & 0.962 \\
\hline & $\operatorname{Dim} 13$ & Dim 14 & Dim 15 & $\operatorname{Dim} 16$ & & \\
\hline Eigenvalue & 0.002 & 0.001 & 0.001 & 0.001 & & \\
\hline Correlation & 0.042 & 0.034 & 0.032 & 0.027 & & \\
\hline Contribution rate & 0.014 & 0.009 & 0.008 & 0.006 & & \\
\hline $\begin{array}{l}\text { Cumulative } \\
\text { contribution rate }\end{array}$ & 0.976 & 0.986 & 0.994 & 1 & & \\
\hline
\end{tabular}

Based on the above judgment, another new CA was carried out using the same seventeen Japanese EFL textbooks variants, excluding Seisoku-3, i.e., sixteen historical textbooks and one current textbooks, the aim, method and procedure 
being the same as in the previous 18-variant CA. The following were the obtained results. Table 4 shows the basic statistics of the present CA, i.e., the eigenvalues, coefficient correlations, contribution rates and cumulative contribution rates of the analysis. As the contribution rate indicates in Table 4, the distinctive features of the seventeen nominal variants (textbooks) were explained $28.4 \%$ by the first dimension, $16.3 \%$ by the second dimension, $10.2 \%$ by the third dimension, $9.1 \%$ by the fourth dimension, $7.7 \%$ by the fifth dimension, $6 \%$ by the sixth dimension and 5.4 by the seventh dimension, the cumulative contribution rate being $83.1 \%$ on the seventh dimension. This means that seven dimensions should be sufficient enough for the analysis and interpretation of the present results.

Table 5 shows the values of the seventeen textbook variants on Dim 1 as a description of the relationships among the seventeen variants on Dim 1. As it is clear in Table 5, on the first dimension, the value is the highest for Dening-3 (1.219), the second highest for Kanda-p3 (0.861) and the third highest for Union-3 (0.725), while it is the lowest for Mombusho-p3 (--3.004), the second lowest for Inoue-p3 (-1.601) and the third lowest for Sunshine-3 (-0.656). In decreasing order, the seventeen textbooks were: Dening-3 $>$ Kanda-p3> Union-3 $>$ Drill-3 $>$ Choice-3 $>$ Globe-3 > Standard (t)-3 > Kanda-3> National-3> Standard( $p$ )-3 > Taisho-3 > Tsuda-p3 > JackEBetty-3 > Pacific-3 > Sunshine-3 > Inoue-p3 > Mombusho-p3. (Incidentally, the order on Dim 1 in the Book-1 CA results (eighteen textbooks) was: Dening-1 $>$ Union-1 $>$ National-1 $>$ Choice-1 $>$ Standard $(t)-1>$ Inoue- $p 1>$ Seisoku-1 > Globe-1 > Tsuda-p1 > Standard $(p)-1>$ Drill-1 $>$ Taisho-1 $>$ Pacific-1 $>$ Mombusho-p1 > JackEBetty-1 > Kanda-p1 > Kanda-1 > Sunshine-1 (Honda et al., 2018).)

Table 5: Values on Dim 1

\begin{tabular}{|l|r|}
\hline & Dim 1 \\
\hline Dening-3 & 1.219 \\
\hline Kanda-p3 & 0.861 \\
\hline Union-3 & 0.725 \\
\hline Drill-3 & 0.633 \\
\hline Choice-3 & 0.586 \\
\hline Globe-3 & 0.53 \\
\hline Standard(t)-3 & 0.5 \\
\hline Kanda-3 & 0.39 \\
\hline National-3 & 0.281 \\
\hline Standard(p)-3 & 0.228 \\
\hline Taisho-3 & 0.178 \\
\hline Tsuda-p3 & 0.044 \\
\hline Jack\&Betty-3 & -0.326 \\
\hline Pacific-3 & -0.52 \\
\hline Sunshine-3 & -0.656 \\
\hline Inoue-p3 & -1.601 \\
\hline Mombusho-p3 & -3.004 \\
\hline
\end{tabular}

The distribution of these seventeen textbooks on the first dimension could clearly be explained by the category of difficult (+) vs. easy (-) texts; in Dening-3 (the highest), Kanda-p3 (the second highest), Union-3 (the third highest) and the other high-scoring textbooks, the texts were difficult since the grammatical and 
lexical items were not strictly controlled there, while in Mombusho-p3 (the lowest), Inoue-p3 (the second lowest), Sunshine-3 (the third lowest) and the other low-scoring textbooks, the texts were easy since they were written using a small, limited number of basic grammatical and lexical items in every lesson.

For example, when the following two pieces taken from the two contrasting textbooks, Dening-3 (the most difficult) and Mombusho-p3 (the easiest), are compared, it is obvious that in Dening-3 the texts sound more natural and therefore more challenging for fresh EFL learners and their readability is contrastively high while Mombusho-p3 uses easy and basic vocabulary and grammatical structure repeatedly. For this reason, the first dimension was termed difficult vs. easy texts, just as in the Book- 1 set (Honda et al., 2018). The contribution rate of the first dimension was 0.284 , covering the $28.4 \%$ of the whole contribution.

"TOWARDS the close of the last century, in the fourth block of houses at Yushima, Edo, there lived a man called SABUROBEI. He got his living by purchasing and selling at a profit scraps of old paper. He was, however, very poor, and it was all he could do to maintain himself and his wife and child.

When the child reached the age of nine, whilst playing one day, he was stolen. The man who took him immediately set out for Mutsu. Day by day, as they proceeded on the journey, the boy picked up all the pieces of paper that he saw on the road. The man who had carried him off asked him why he did this. "My father," he replied," gets his living by selling old paper, and so I have been thinking that, if I pick up a quantity of paper on the road and send it back to him, he will be very pleased."" Dening-3, Lesson 1 (The most difficult)

“1. Good morning, Charles.

2. Hallo, Henry! Good morning.

3. How are you getting on now-a-days?

4. Very nicely, thank you.

5. How do you do, Jennie?

6. I am quite well, thank you.

7. Is your brother in good health?

8. No, he is not so well as he used to be.

9. What is the trouble?

10. He seems to have some trouble with his stomach." Mombusho-p3, Lesson 1 (The easiest)

It is to be noted concerning the feature of Dim 1 that this CA readability judgment is not a direct, measurement-based estimation like readability measurement but an indirect one, based on a highly advanced correlation-based 
mathematical processing of cross-frequency tabulation of the top one-hundred words of the seventeen textbooks. In order to ascertain the degree of accuracy of this CA estimation, the degree of readability of the seventeen textbooks were actually measured using the newest readability measuring tool, Ozasa-Fukui Year Level, Ver. 3.5nhnc1-6, and the results were compared with the present CA results.

Ozasa-Fukui Year Level, Ver. 3.5nhnc1-6 is a readability measuring tool jointly developed in Japan by T. Ozasa (one of the authors of the present paper) and M. Fukui (developer of a statistic application tool, College Analysis used in the present analysis) for Japanese EFL teachers and educators. The function equation (NewDiff) of Ozasa-Fukui Year Level, Ver. 3.5nhnc1-6 was as follows, where Words stands for number of words in a sentence, Syllables number of syllables in a word, WordDiff difficulty of a word, and IdiomDiff difficulty of an idiom, and its prediction rate turned out to be 8912 (Ozasa, Watanabe \& Fukui (2016, p. 392).

NewDiff $=5.2565^{*} \exp \left(-19.1656^{*} 0.4398^{\wedge}\right.$ Diff $)+1\left(r^{\wedge} 2=0.8912\right)$

Diff $=0.0924 *$ Words $+0.5862 *$ Syllables $+1.8296 *$ WordDiff $+0.0615^{*}$ IdiomDiff- 0.3073

$\left(r^{\wedge} 2=0.4986\right)$

Words: number of words in a sentence

Syllables: number of syllables in a word

WordDiff difficulty of a word

IdiomDiff difficulty of an idiom

In this system, WordDiff was defined as the year of a textbook in which a particular word appeared for the first time and IdiomDiff as the year of a textbook in which a particular idiom appeared for the first time. It has to be noted that this is a two-step development process comprised of (1) liner function development (development of Diff) and (2) non-linear function development (development of NewDiff), the combination of which we believe contributed to its fairly high validity with its powerful prediction rate $\left(\mathrm{r}^{\wedge} 2=.8912\right)$ (Ozasa et al., 2016, p. 392; Honda, et al., 2018).

Table 6 shows the readability values of the seventeen textbooks as measured by Ozasa-Fukui Year Level, Ver. 3.5nhnc1-6. In order to examine the degree of correspondence between the two measurements, the Dim 1 estimation and the Ozasa-Fukui Year Level estimation, a rank correlation coefficient or Spearman's rho was computed between them. The correlation coefficient computed proved to be $.696(\mathrm{p}<.001)$, which does not seem to be a high, but a medium degree of correlation or correspondence in rank order. This might suggest that the analysis was not as accurate as those of the other recent CA studies, such as .8802 in the CA with nine Japanese historical EFL textbooks (Book 1) and their current counterpart (Honda et al., 2017) and $.804(\mathrm{p}<.001)$ in the CA with 
seventeen Japanese historical EFL textbooks (Book 1) and their current counterpart (Honda et al., 2018).

Table 6: Readability Measured by OFYL

\begin{tabular}{|l|r|}
\hline & \multicolumn{1}{|c|}{ OFYL } \\
\hline Dening-3 & 6.94 \\
\hline Union-3 & 6.71 \\
\hline Globe-3 & 6.63 \\
\hline Choice-3 & 6.04 \\
\hline Standard(p)-3 & 5.95 \\
\hline Standard(t)-3 & 5.91 \\
\hline Kanda-3 & 5.87 \\
\hline National-3 & 5.32 \\
\hline Kanda-p3 & 5.16 \\
\hline Tsuda-p3 & 5.04 \\
\hline Pacific-3 & 5.03 \\
\hline Inoue-p3 & 3.96 \\
\hline Taisho-3 & 3.91 \\
\hline Jack\&Betty-3 & 3.75 \\
\hline Drill-3 & 3.69 \\
\hline Mombusho-p3 & 3.68 \\
\hline Sunshine-3 & 3.30 \\
\hline
\end{tabular}

It could be argued that the indirect readability estimation of the CA is reasonably accurate, on two grounds. First, the accuracy rate (prediction rate, $\mathrm{r}^{\wedge} 2$ ) of Ozasa-Fukui Year Level, Ver. 5nhnc1-6 is .8912 or $89.12 \%$, which means that there are about $11 \%$ chances of errors in its estimation itself (Ozasa et al., 2016; Kawamura et al., 2017, p. 74). Second, the seventeen corpora used in the two analyses were not the same in the strict sense of the word; in the present CA, the whole corpora were used without any kinds of modification, while in the direct readability measurement, the corpora were "cleaned" or processed, in which unnecessary, irrelevant parts of the passages were deleted so that only "normal" sentences could be measured. All of these facts considered, it must be concluded, the estimation of the present CA judgment of the eighteen corpora is reasonably accurate, accurate enough for the purpose of the present study. (Honda et al., 2017; Honda et al., 2018)

This conclusion, or the present judgment of the Dim 1 results could be generalized to the judgments of the other six dimensions (Dims 2 to 7); in spite of the fact that they are indirect estimation of the textbook features, it could be reasonably accurate and trustworthy estimation and interpretation of their features, accurate enough to satisfy the goal of the present study. (Honda et al., 2017; Honda et al., 2018) 
Table 7: Values on Dim 2

\begin{tabular}{|l|r|}
\hline & Dim 2 \\
\hline Sunshine-3 & 1.762 \\
\hline Standard(p)-3 & 1.728 \\
\hline Standard(t)-3 & 1.425 \\
\hline Globe-3 & 1.285 \\
\hline Dening-3 & 0.681 \\
\hline Inoue-p3 & 0.485 \\
\hline Tsuda-p3 & 0.011 \\
\hline Choice-3 & -0.13 \\
\hline Jack\&Betty-3 & -0.289 \\
\hline Pacific-3 & -0.416 \\
\hline Drill-3 & -0.458 \\
\hline Mombusho-p3 & -0.67 \\
\hline National-3 & -0.799 \\
\hline Kanda-p3 & -1.017 \\
\hline Kanda-3 & -1.094 \\
\hline Taisho-3 & -1.104 \\
\hline Union-3 & -1.336 \\
\hline
\end{tabular}

On the second dimension, as it is clear in Table 7, the value was the highest for Sundhine-3 (1.762), the second highest for Standard(p)-3 (1.728), while it is the lowest for Union-3 (-1.336) and the second lowest for Taisho-3 (-1.104), Tsuda-p3 being around the zero point. In decreasing order, the seventeen textbooks were: Sunshine-3 $>$ Standard( $p$ )-3 $>$ Standard( $t)-3>$ Globe-3 $>$ Dening-3 $>$ Inoue- $p 3>$ Tsudap3 $>$ Choice-3 $>$ JackEBetty-3 $>$ Pacific-3 $>$ Drill-3 $>$ Mombusho-p3 $>$ National-3 $>$ Kanda-p3>Kanda-3 > Taisho-3 $>$ Union-3.

The differences / similarities of the values among the seventeen textbooks on Dim 2 could best be explained by the category of natural-sounding (+) vs. artificial-sounding (-) discourse. As it is clear in the following examples, in Sunshine-3 (the highest) and Standard(p)-3 (the second highest), and other highscoring ones, the discourses sound all natural in tone, as in Sunshine-1 and Dening-1. In contrast, in Union-3 (the lowest), Taisho-3 (the second lowest) and other low-scoring ones, the discourses sound all less-natural or artificial. In other words, Union-3 and other low-scoring ones observe the principle of 'pattern drill first', while Sunshine-3 and other high-scoring ones observe the principle of 'free communication first' as a basic strategy for the EFL textbook organization. For example, as in the following examples, in Sunshine-3 and Standard(p)-3, the dialogs do sound natural, while in Union-3 and Taisho-3, the discourses sound more artificial due to the numbering (Union-3) or repeated exposition of the new time-table (Taisho-3).

"Kumi: How can I get to your house?

John: When you come out of the station, turn right.

Kumi: Yes. 
John: Walk one block and then turn left. Keep walking for about twenty meters and you'll find my house on your left... between a fruit store and a restaurant.

Kumi: Between a fruit store and a restaurant. O.K. Thank you, John. See you then.

John: See you." Sunshine-3, Program 1 (The most natural-sounding discourse)

"A long time ago the people in Britain (the country that is now called England) thought that there was no other country in the world but theirs, and no other people but themselves. Other people in different parts of the world used to think the same thing about their countries and themselves. They did not travel from country to country as we do now, so they could not get to know of far-off places and different people." Standard $(p)-3$, Program 1 (The second most natural-sounding discourse)

"1. FANNY was a bright little girl, and could learn very fast. Her mother had taken great pains to teach her at home, and she could read well in SANDERS' UNION READER, NUMBER TWO, before she was seven years of age.

2. Fanny's mother bought twenty-six cards, which had the letters of the alphabet printed on them, and told her she must take them, and teach her little brother Frank these letters, so that he could go to school, and learn to read too." Union-3, Lesson 1 (The most artificial-sounding discourse)

\section{“THE NEW TIME-TABLE.}

We are now in the third year class.

We had holiday yesterday, but school begins to-day.

We shall have some new lessons.

We are to have chemistry twice a week. Our teacher of chemistry says he will show us some interesting experiments. I wonder what they are like.

We have arithmetic two hours a week. I think arithmetic is very difficult.

Once a week we have morals, etiquette, drawing, and geography." Taisho-3, Lesson 1 (The second most artificial-sounding discourse) 
For this reason, the second dimension was termed natural-sounding vs. artificial-sounding discourse, just as in the Book-1 CA results (Honda et al., 2018). The contribution rate of the second dimension was 0.163 , covering the $16.3 \%$ of the whole contribution.

Table 8: Values on Dim 3

\begin{tabular}{|l|r|}
\hline & \multicolumn{1}{|l|}{ Dim 3 } \\
\hline Sunshine-3 & 2.016 \\
\hline Pacific-3 & 1.119 \\
\hline Tsuda-p3 & 1.074 \\
\hline Jack\&Betty-3 & 0.807 \\
\hline National-3 & 0.76 \\
\hline Taisho-3 & 0.62 \\
\hline Union-3 & 0.486 \\
\hline Inoue-p3 & 0.213 \\
\hline Kanda-p3 & 0.189 \\
\hline Globe-3 & -0.437 \\
\hline Choice-3 & -0.439 \\
\hline Standard(p)-3 & -0.47 \\
\hline Drill-3 & -0.496 \\
\hline Standard(t)-3 & -0.72 \\
\hline Kanda-3 & -1.284 \\
\hline Dening-3 & -1.585 \\
\hline Mombusho-p3 & -1.78 \\
\hline
\end{tabular}

On the third dimension, as it is clear in Table 8 , the value is the highest for Sunshine-3 (2.016), the second highest for Pacific-3 (1.119) and the third highest for Tsuda-p3 (1.074), and the lowest for Mombusho-p3 (-1.78), the second lowest for Dening-3 (-1.585), Kanda-p1 and others coming in between them. In decreasing order, the seventeen textbooks were: Sunshine-3 $>$ Pacific-3 $>$ Tsuda-p3 $>$ JackEBetty-3 > National-3 > Taisho-3 > Union-3 > Inoue-p3 > Kanda-p3 > Globe-3 > Choice-3 $>$ Standard $(p)-3>$ Drill-3 $>$ Standard(t)-3>Kanda-3>Dening-3>Mombushop3.

The differences / similarities among these seventeen textbooks on Dim 3 could best be explained by the category of dialogue-based (+) vs. passage-based (-) textbooks. As it is clear in the following examples, Sunshine-3 (the highest), Pacific-3 (the second highest) and other high-scoring ones favor dialogues more frequently throughout their lessons. On the contrary, Mombusho-p3 (the lowest), Dening-3 (the second lowest), and other low-scoring ones favor expository passages more frequently throughout their texts, without exceptions. For example, as in the following examples, Sunshine-3 and Pacific-3, the high-scoring ones, prefer and adopt dialogue-based discourses, while Mombusho-p3 and Dening-3, the low-scoring ones, passage-based discourses.

"Kumi: How can I get to your house?

John: When you come out of the station, turn right.

Kumi: Yes. 
John: Walk one block and then turn left. Keep walking for about twenty meters and you'll find my house on your left... between a fruit store and a restaurant.

Kumi: Between a fruit store and a restaurant. O.K. Thank you, John. See you then.

John: See you." Sunshine-3, Program 1 (The most dialogue-based discourse)

"On the Ground. (Fred and I went to the aerodrome and met Uncle George in his flying dress.)

Fred. Good Morning, Uncle.

Uncle. Hullo, Fred! Oh, Edith, you've come, too.

Edith. I thought it would be fun to go up with you.

Uncle. What a brave little girl, my dear! Come along, then. Take this back seat, Fred. Take the seat beside him, Edith. Now let me make both of you secure.

(Strapping them in.) Is this all right?

Fred. Thank you very much.

Uncle. Are you ready? Let's start.

Edith. (Laughing). I'm a little afraid, brave girl as I am. Going Up.

Uncle. Here we go!

Fred. How do you feel, Edith?" Pacific-3, Lesson 3 (The second most dialogue-based discourse)

"1. These are school-children.

2. Some of them are boys, and the others are girls.

3. The boys and the girls go to the same school.

4. Do you think they are all in the same class?

5. O no! The big ones are in the higher class, and the little ones are in the lower class." Mombusho-p3, Lesson 2 (The most passage-based discourse) 
"TOWARDS the close of the last century, in the fourth block of houses at Yushima, Edo, there lived a man called SABUROBEI. He got his living by purchasing and selling at a profit scraps of old paper. He was, however, very poor, and it was ail he could do to maintain himself and his wife and child." Dening-3, Lesson 1 (The second most passagebased discourse)

It has to be noted in this respect that the feature of Dim 3, or the axis of dialoguebased (+) vs. passage-based (-) textbooks proved to be the same as that of the Book-1 results except that the plus-minus of the axis was reversed in the present analysis(Honda et al., 2018). The contribution rate of the third dimension was 0.102 , covering only the $10.2 \%$ of the whole contribution.

Table 9: Values on Dim 4

\begin{tabular}{|l|r|}
\hline & Dim 4 \\
\hline Inoue-p3 & 2.651 \\
\hline Pacific-3 & 0.829 \\
\hline Globe-3 & 0.65 \\
\hline Drill-3 & 0.621 \\
\hline National-3 & 0.469 \\
\hline Choice-3 & 0.394 \\
\hline Standard(t)-3 & 0.222 \\
\hline Standard(p)-3 & 0.154 \\
\hline Tsuda-p3 & -0.067 \\
\hline Union-3 & -0.169 \\
\hline Taisho-3 & -0.208 \\
\hline Kanda-3 & -0.335 \\
\hline Jack\&Betty-3 & -0.631 \\
\hline Kanda-p3 & -0.653 \\
\hline Dening-3 & -0.8 \\
\hline Mombusho-p3 & -1.31 \\
\hline Sunshine-3 & -2.091 \\
\hline
\end{tabular}

On the fourth dimension, as it is clear in Table 9, the value is the highest for Inoue-p3 (2.651), the second highest for Pacific-3 (0.829) and the third highest for Globe-3 (0.65), while it is the lowest for Sunshine-3 (-2.091), the second lowest for Mombusho-p3 (-1.31) and the third lowest for Dening-3 (-0.8), the other textbooks being between them. In decreasing order, the seventeen textbooks were: Inouep3 $>$ Pacific-3 $>$ Globe-3 $>$ Drill-3 $>$ National-3 $>$ Choice-3 $>$ Standard( $t)-3>$ Standard(p)-3 > Tsuda-p3 > Union-3 > Taisho-3 > Kanda-3 > JackEBetty-3 > Kandap3 $>$ Dening-3 $>$ Mombusho-p3 $>$ Sunshine-3.

The differences / similarities among these seventeen textbooks on Dim 4 could best be explained by the category of teacher-dominance $(+)$ vs. non teacherdominance (-). As it is clear in the following examples cited from Inoue-p3 (the highest), not a few texts are comprised of dialogs in which a teacher or a 
superior dominates pupils or inferiors in the whole linguistic activity, while in Sunshine-3 (the lowest), Mombusho-p3 (the second lowest) and other low-scoring textbooks there were few such features observed in the texts. For this reason, the fourth dimension was termed teacher-dominance vs. non teacher-dominance, just as in the Book-1 results (Honda et al., 2018). The contribution rate of the fourth dimension was 0.091 , covering only the $9.1 \%$ of the whole contribution.

"Have you ever seen a fox? Yes, I saw one the other day. Where did you see it? It was near our house. What was it doing? It was looking at the hens in our yard. And did it catch any of them? No; for our dog saw it and ran after it. Did the dog catch it? No, the fox escaped into a wood close by." Inoue-p3, Lesson 1 (The most teacher-dominant)

Table 10: Values on Dim 5

\begin{tabular}{|l|r|}
\hline & \multicolumn{1}{|l|}{ Dim 5 } \\
\hline Tsuda-p3 & 2.213 \\
\hline Taisho-3 & 1.358 \\
\hline Globe-3 & 1.219 \\
\hline Kanda-3 & 1.002 \\
\hline Standard(t)-3 & 0.856 \\
\hline National-3 & 0.436 \\
\hline Mombusho-p3 & 0.269 \\
\hline Standard(p)-3 & 0.204 \\
\hline Union-3 & -0.338 \\
\hline Pacific-3 & -0.375 \\
\hline Kanda-p3 & -0.555 \\
\hline Inoue-p3 & -0.704 \\
\hline Sunshine-3 & -0.73 \\
\hline Dening-3 & -0.929 \\
\hline Choice-3 & -0.944 \\
\hline Jack\&Betty-3 & -1.299 \\
\hline Drill-3 & -1.341 \\
\hline
\end{tabular}

On the fifth dimension, as it is clear in Table 10, the value is the highest for Tsuda-p3 (2.213), the second highest for Taisho-3 (1.358), and the lowest for Drill-3 $(-1.341)$ and the second lowest for Jack\&Betty-3 (-1.299), the others coming in between them. In decreasing order, the seventeen textbooks were: Tsuda-p3 > Taisho-3 > Globe-3 > Kanda-3 > Standard(t)-3 > National-3 > Mombusho-p3 > Standard(p)-3 > Union-3 > Pacific-3 $>$ Kanda-p3 $>$ Inoue-p3 $>$ Sunshine-3 $>$ Dening-3 $>$ Choice-3 $>$ JackEBetty-3 $>$ Drill-3.

The difference of the values among the seventeen textbooks on Dim 5 could best be explained by the category of strictly-controlled (+) vs. loosely-controlled (-) texts. In Tsuda-p3 (the highest), Taisho-3 (the second highest) and other highscoring ones, linguistic items were rather selected or controlled and grammatical and lexical items were sometimes carefully focused after the text / discourse for each lesson or unit, while in Drill-3 (the lowest) and JackEBetty-3 (the second 
lowest), and other low-scoring ones this kind of linguistic control was not strictly observed, giving more freedom for natural communication and communicative activity. In other words, Tsuda-p3 observes the principle of a step-by-step progression, while Drill-3, JackEBetty-3 and other low-scoring textbooks observes the principle of freer communication as a basic strategy of EFL textbook organization. For this reason, the fifth dimension was termed strictly-controlled vs. loosely-controlled texts, just as in the Book-1 results (Honda et al., 2018). The name, feature and axis of the fifth dimension were basically the same as those of the results of Book-1 CA (Honda et al, 2018). The contribution rate of the fifth dimension was 0.077 , covering only $7.7 \%$ of the whole contribution.

Table 11: Values on Dim 6

\begin{tabular}{|l|r|}
\hline & \multicolumn{1}{|l|}{ Dim 6 } \\
\hline Kanda-3 & 2.923 \\
\hline Sunshine-3 & 1.582 \\
\hline Inoue-p3 & 1.185 \\
\hline Taisho-3 & 0.625 \\
\hline Drill-3 & 0.447 \\
\hline Kanda-p3 & -0.042 \\
\hline Choice-3 & -0.156 \\
\hline Dening-3 & -0.27 \\
\hline Standard(t)-3 & -0.27 \\
\hline Tsuda-p3 & -0.562 \\
\hline Globe-3 & -0.614 \\
\hline Standard(p)-3 & -0.632 \\
\hline Pacific-3 & -0.638 \\
\hline Union-3 & -0.786 \\
\hline Jack\&Betty-3 & -0.79 \\
\hline National-3 & -0.884 \\
\hline Mombusho-p3 & -0.949 \\
\hline
\end{tabular}

On the sixth dimension, as it is clear in Table 11, the value is the highest for Kanda-3 (2.923), the second highest for Sunshine-3 (1.582), the third highest for Inoue-p3 (1.185), and the lowest for Mombusho-p3 (-0.949) and the second lowest for National-3 (-0.884), the others coming in between them. In decreasing order, the seventeen textbooks were: Kanda-3 $>$ Sunshine-3 $>$ Inoue-p3 $>$ Taisho-3 $>$ Drill$3>$ Kanda-p3 $>$ Choice-3 $>$ Dening-3 $>$ Standard( $t)-3>$ Tsuda-p3 $>$ Globe-3 $>$ Standard(p)-3 > Pacific-3 > Union-3 > JackEBetty-3 > National-3 > Mombusho-p3.

The difference of the values among the seventeen textbooks Dim 6 could best be explained by the category of redundant $(+)$ vs. concise (-) texts; in Kanda-3 (the highest) and other high-scoring ones, a considerably large part of the texts tend to be long and to sound some redundant in the sense that the dialogues and expository passages are interwoven with other related drill-based repetitive learning activities such as grammar, structure, Japanese into English translation, spelling, etc. (especially in Kanda-3 and Inoue-p3) or some of the discourses are 
longer and somewhat desultory while in Mombusho-p3 (the lowest) and other low-scoring textbooks the passages and dialogues were generally brief and comprehensive without tedious repetitive drill-like sentences.

Table 12: Values on Dim 7

\begin{tabular}{|l|r|}
\hline & Dim 7 \\
\hline Pacific-3 & 2.309 \\
\hline Kanda-p3 & 1.593 \\
\hline Standard(t)-3 & 0.743 \\
\hline National-3 & 0.653 \\
\hline Kanda-3 & 0.572 \\
\hline Drill-3 & 0.413 \\
\hline Standard(p)-3 & 0.229 \\
\hline Globe-3 & 0.182 \\
\hline Mombusho-p3 & 0.166 \\
\hline Sunshine-3 & 0.003 \\
\hline Choice-3 & -0.241 \\
\hline Taisho-3 & -0.717 \\
\hline Jack\&Betty-3 & -0.759 \\
\hline Dening-3 & -0.956 \\
\hline Tsuda-p3 & -0.972 \\
\hline Inoue-p3 & -1.134 \\
\hline Union-3 & -1.791 \\
\hline
\end{tabular}

For this reason, the sixth dimension was termed redundant vs. concise texts, just as in the Book-1 results (Honda et al., 2018). It has to be noted in this respect that the name, feature and axis of the sixth dimension were basically the same as in the results of Book-1 CA except for the fact that the location of the plus-minus of the axis was altered between the present analysis and theBook-1 CA. The contribution rate of the sixth dimension was 0.060 , covering only $6.0 \%$ of the whole contribution.

On the seventh dimension, as it is clear in Table 12, the value is the highest for Pacific-3 (2.309), the second highest for Kanda-p3 (1.593), the third highest for Standard(t)-3 (0.743), and the lowest for Union-3 (-1.791), the second lowest for Inoue-p3 (-1.134) and the others coming in between them. In decreasing order, the seventeen textbooks were: Pacific-3 $>$ Kanda-p3 $>$ Standard( $t)-3>$ Nattional $-3>$ Kanda-3 $>$ Drill-3 $>$ Standard(p)-3 $>$ Globe-3 $>$ Mombusho-p3 $>$ Sunshine-3 $>$ Choice-3 $>$ Taisho-3 > JackEBetty-3 > Dening-3 > Tsuda-p3 > Inoue-p3 > Union-3. 


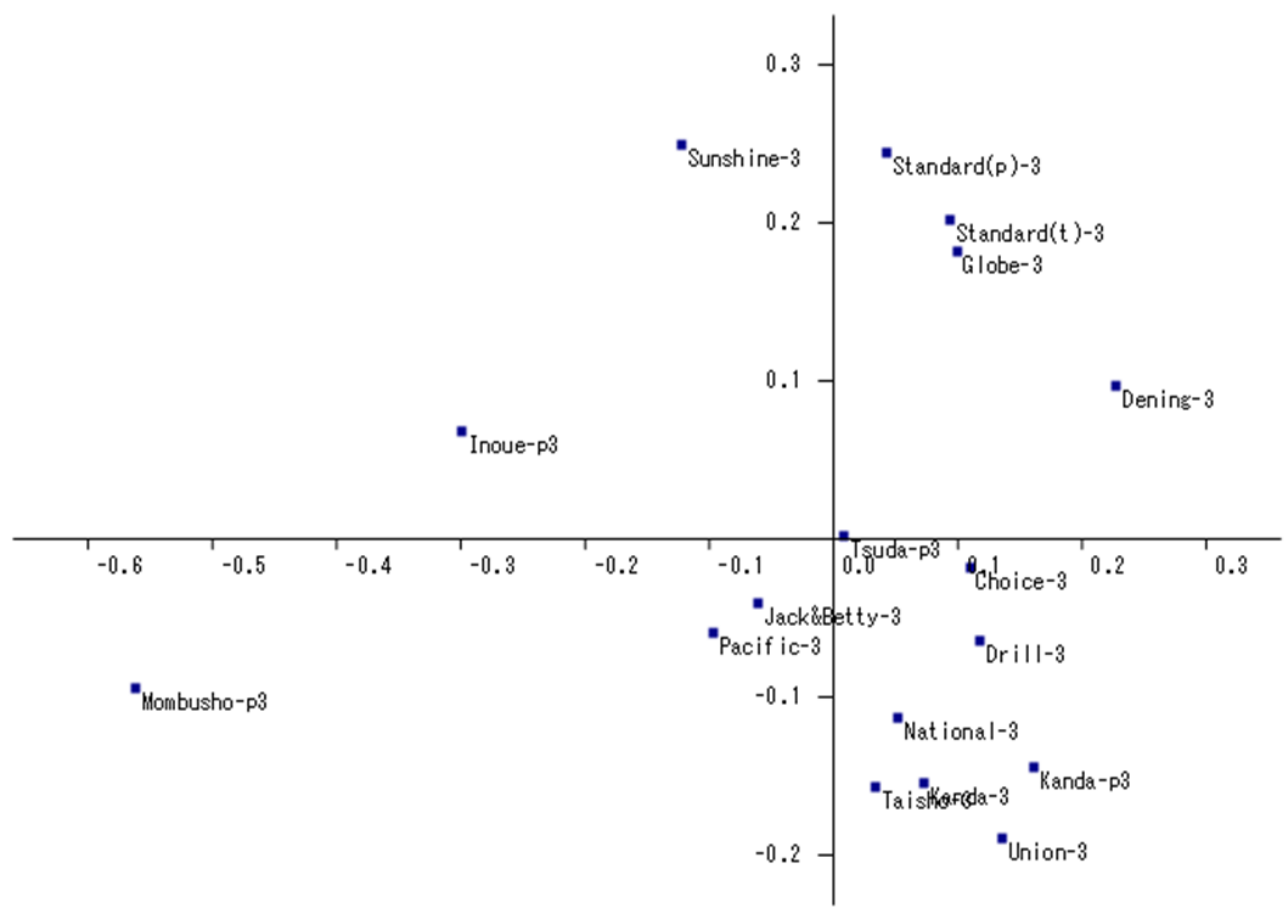

X-axis: difficult (+) vs. easy (-) texts

Y-axis: natural-sounding (+) vs. artificial-sounding discourse (-)

Figure 2: CA Map of 17 Textbooks

The difference of the values among the seventeen textbooks on Dim 7 could best be explained by the category of connected $(+)$ vs. disconnected (-) contents. In Pacific-3 (the highest), Kanda-p3 (the second highest) and other high-scoring ones, the contents of the passages in the lessons are connected and especially in Pacific3 the same characters such as Edwin, Harry, Kate, etc., sometimes appear throughout the whole texts, while in Union-3 (the lowest), Inoue-p3 (the second lowest) and others, the discourses are separated or disconnected in some way or other. In Union-3, for example, the whole texts are separated by the numbering of sentences/ passages and in Inoue-p3 and others a considerably large part of the texts, lessons are disconnected by other unrelated activities such as 'Helps to Study.' For this reason, the seventh dimension was termed connected vs. disconnected contents, just as in the Book-1 CA (Honda et al., 2018). The contribution rate of the seventh dimension was 0.054 , covering only $5.4 \%$ of the whole contribution.

As a summary of the above descriptions and discussions, the CA map in Figure 2 visualizes the $44.6 \%$ of the spatial relationships among the seventeen nominal variants or textbooks in focus, in which the $x$-axis represents the first dimension or the axis of difficult (+) vs. easy (-) texts and the $y$-axis the second dimension or 
the axis of natural-sounding $(+)$ vs. artificial-sounding (-) discourses. (Because these dimensions are the top two of the seven dimensions specified, covering almost a half of the whole contribution rates, they can be regarded as the major dimensions among the seven dimensions in the present CA results.) As it is clear in Figure 2, all of the seventeen textbooks were clearly classified into four groups, (1) plus(x)-plus(y) group, (2) minus(x)-plus (y) group, (3) plus (x)minus(y) group, and (4) minus (x)-minus (y) group, as in the following classification.

$\begin{array}{ll}\text { Group } 1 \text { (plus(x)-Plus (y)) } & \text { Group } 2 \text { (minus(x)-plus (y)) } \\ \text { Standard }(p)-3 & \text { Sunshine-3 } \\ \text { Standard }(t)-3 & \text { Inoue-3 } \\ \text { Globe-3 } & \\ \text { Dening-3 } & \\ \text { Tsuda-p3 } & \\ \text { Group 3 (plus (x)-minus(y)) } & \text { Group 4 (minus (x)-minus (y)) } \\ \text { Choice-3 } & \text { JackEBetty-3 } \\ \text { Drill-3 } & \text { Pacific-3 } \\ \text { National-3 } & \text { Mombusho-p3 } \\ \text { Kanda-p3 } & \\ \text { Kanda-3 } & \\ \text { Taisho-3 } & \\ \text { Union-3 } & \end{array}$

As it is clear in the above classification, Group 1, which is characterized by difficult and natural-sounding texts, was comprised of five textbooks, i.e., Standard(t)-3, Standard(t)-3, Globe-3, Dening-3 and Tsuda-p3. Group 2, which is characterized by easy and natural-sounding texts, was comprised of two textbooks, i.e., Sunshine-3 and Inoue-3. Group 3, which is characterized by difficult and artificial-sounding texts, was comprised of seven textbooks, i.e., Choice-3, Drill-3, National-3, Kanda-p3, Kanda-3, Taisho-3 and Union-3. Group 4, which is characterized by difficult and artificial-sounding texts, was comprised of three textbooks, i.e., JackEBetty-3, Pacific-3 and Mombusho-p3.

Clearly, it was both Dim 1, the axis of difficult (+) vs. easy (-) texts and Dim 2, the axis of natural-sounding $(+)$ vs. artificial-sounding (-) discourses that differentiated the seventeen textbooks from each other. This will prove that both of the two axes, both $\mathrm{x}$-axis and $\mathrm{y}$-axis are also efficient and powerful differentiators of the seventeen EFL textbooks in focus. 
It is interesting to note in this respect that in the above CA map, only two textbooks, Sunshine-1, a current textbook, and Inoue-p3, a historical textbook for primary school, were located at a zone (minus(x)-plus (y)) distinctively different from the other fifteen historical textbooks in terms of the two dimensions, i.e., difficult / easy texts and naturalness / artificiality. Although Inoue-p3 and Sunshine-3 were easy in difficulty, they were not artificial discourses as in the case of the other historical textbooks, but proved to be natural-sounding.

What is noticeable with this result is the fact that only two textbooks, Snshine-3 and Inoue-p3, one current and the other historical, were separated from the other fifteen historical textbooks by two features, i.e., difficulty / easiness (Dim 1) and naturalness / artificialness (Dim 2). Indeed, these two kinds of features, which are the characteristic features of the current EFL textbook, Sunshine-3, are also shared by only one historical textbook, Inoue-p3, among sixteen ones. This might suggest that Inoue-p3 was a forerunner of new historical textbooks seeking to be more user-friendly for Japanese EFL learners struggling in the English class in those days.

It is true that the CA map based on the two selected major dimensions (axes) can differentiate the major features of the seventeen historical and current EFL textbooks but naturally it cannot differentiate visually all of their features detected in the analysis. As it is clear in the cumulative contribution rates in Table 1, the CA map comprised of two dimensions, Dim 1 and Dim 2, can only display 44.6 percent of the whole features, leaving the rest $(55.4 \%)$ of the features untouched. In order to overcome this weakness, an attempt was made to display the whole pictures of their features based on the values of the whole dimensions dealt with in the present analysis. It is a way of computing the actual distance (Euclidean distance) of the seventeen individual textbooks on each of the sixteen dimensions, by multiplying the weighted correlation coefficients by the coefficients proportional to the contribution rates. Using the thus-computed Euclidean distances of the seventeen textbooks on the sixteen dimensions, a cluster analysis was performed using College Analysis, by Ward method, so as to draw a dendrogram of the seventeen textbooks. Figure 3 is a dendrogram which visually summarizes the degree of similarities and differences among the seventeen nominal variants of the present analysis, based on the values (distances) of all of the (sixteen) dimensions computed in the present analysis, not based on the results of the two selected dimensions as in Figures 1 and 2.

Dendrogam is a branching diagram like biological taxonomy, representing a hierarchy of categories based on the degree of similarity or the numbers of shared characteristics and graphically displays the internal cohesion and external isolation of the variants in focus, i.e., the seventeen textbooks in the present analysis. (Honda et al., 2017; Honda et al., 2018) 


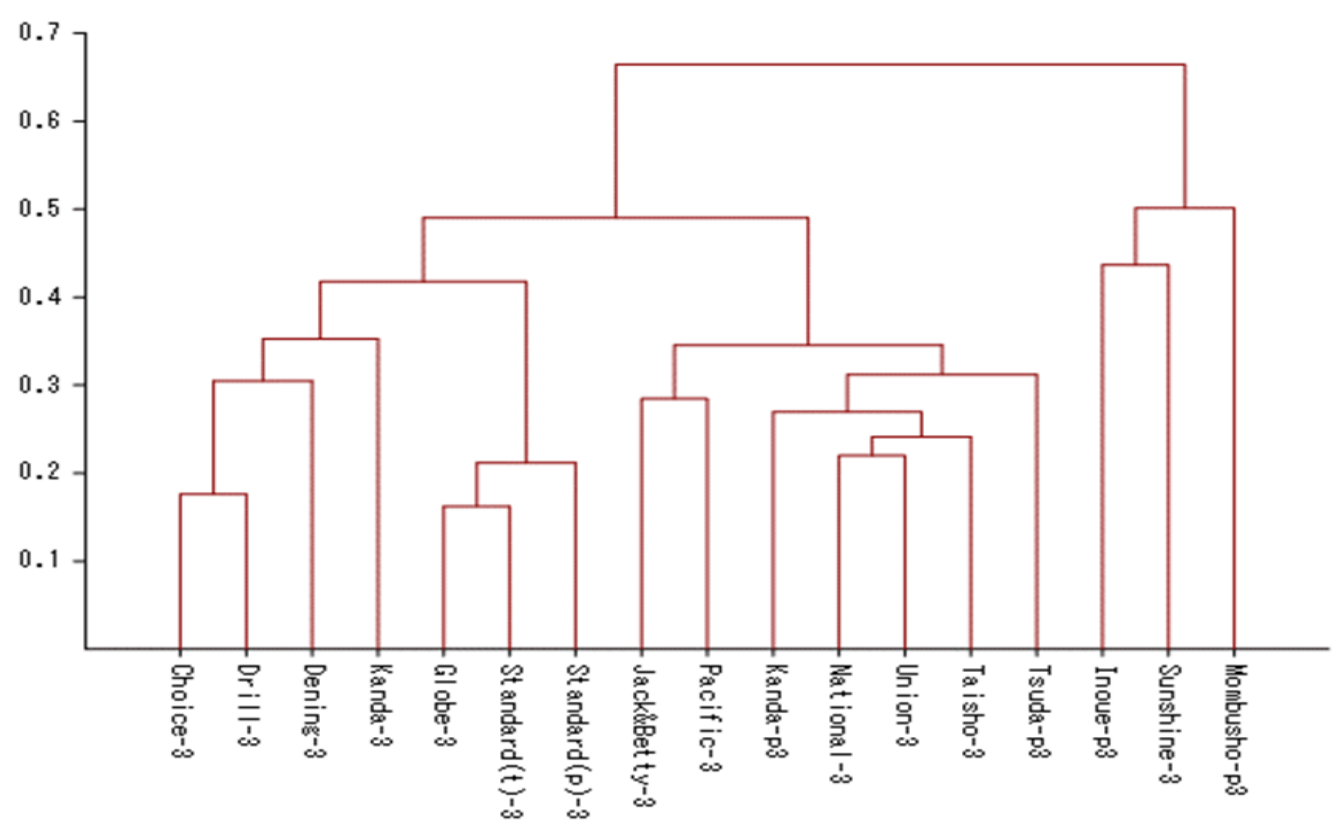

Figure 3: Dendrogram by Ward Method

As Figure 3 shows, the whole features specified in the present analysis were visually summarized in the dendrogram, which can also be described as in the following combination of brackets.

((((((Choice-3, Drill-3) Dening-3) Kanda-3) ((Globe-3, Standard(t)-3) Standard(p)-3))) ((Jack\&Betty-3, Pacific-3) ((Kanda-p3 ((National-3, Union-3) Taisho-3)))) Tsuda-p3))) ((Inoue-p3, Sunshine-3) Mombusho-p3))

As it is clear in Figure 3, there were three clusters formed in this dendrogram, two large clusters comprised of seven textbooks each and one small cluster comprised of three textbooks; one large cluster (Cluster A) comprised of Choice3, Drill-3, Dening-3, Kanda-3, Globe-3, Standard(t)-3 and Standard(p)-3, another large cluster (Custer B) comprised of Jack\&Betty-3, Pacific-3, Kanda-p3, National-3, Union-3, Taisho-3, Tsuda-p3, and a small cluster (Cluster C) comprised of Inouep3, Sunshine-3, and Mombusho-p3. Cluster A and Cluster B were further combined together to form a larger cluster $A B$, which suggests that the last cluster (Cluster C) was distinctively different from the other fourteen textbooks, all of the specified features (categories) considered.

It is interesting to note that on the two-dimensional coordinate representation, only two textbooks, Sunshine-3 and Inoue-p3, were separated as distinctively different from the other fifteen textbooks by the two features, i.e., difficulty / easiness (Dim 1) and naturalness / artificialness (Dim 2), while on the dendrogram covering all of the sixteen features or categories specified, three textbooks, Inoue-p3, Sunshine-3 and Mombusho-p3 were separated as distinctively different from the others. These facts may suggest that all categories considered, 
two textbooks, Inoue-p3 and Mombusho-p3 should be included in the forerunner group represented by the current textbook, Sunshine-3.

\section{Conclusion}

So far, the results of the CA have been analyzed, interpreted and discussed, focusing on the characteristic features, similarities and differences among the seventeen historical and current textbooks, which proved that CA is powerful enough to quantitatively analyze their features. As a summary of the results and discussions of the present CA, the RQs could be answered as in the following.

RQ 1. How similar / different in contents are the sixteen Japanese historical EFL textbooks and their current counterpart to / from each other? The CA results proved capable of differentiating the features of the seventeen textbooks quantitatively, specifying their similarities and differences. In particular, the CA map comprised of Dim 1 and Dim 2 proved powerful enough to differentiate Sunshine-3 and Inoue-p3 from the other fifteen historical textbooks and each of the seventeen textbooks from each other. It was both difficult $(+)$ vs. easy $(-)$ texts (Dim 1) and natural-sounding (+) vs. artificial-sounding (-) discourses (Dim $2)$ that differentiated the seventeen textbooks from each other. This will prove that both of the two axes, (difficult (+) vs. easy (-) texts and natural-sounding $\left(^{+}\right)$ vs. artificial-sounding (-) discourses are also efficient and powerful differentiators of the seventeen EFL textbooks in focus. It is also to be noted that only two textbooks, Snshine-3 and Inoue-p3, one current and the other historical, are separated from the other fifteen historical textbooks by the two features, i.e., difficulty / easiness (Dim 1) and naturalness / artificialness (Dim 2).

$R Q$ 2. What kinds of dimensions explain the similarities / differences among the seventeen textbooks? Their features, or the similarities / differences (distances) among the seventeen textbooks were explained 83.1 percent by the seven dimensions, i.e., difficult vs. easy texts (Dim 1), natural-sounding vs. artificialsounding discourse (Dim 2), dialogue-based vs. passage-based texts (Dim 3), teacher dominance vs. no teacher dominance (Dim 4), strictly controlled vs. loosely controlled texts (Dim 5), redundant vs. concise texts (Dim 6) and connected vs. disconnected contents (Dim 7).

RQ 3. How similar / different in contents are the seventeen Japanese EFL textbooks (Book 3) to / from their first-year counterpart? The similarities / differences of the seventeen Book-3 textbooks were explained by the same dimensions (categories) as those of Book-1 results up to the seventh dimension.

There were, however, small modifications made on Dim3 and Dim 6 in order to explain the obtained data; their axes themselves were the same as in the Book-1 results but their plus-minus location was reversed from those of the Book-1 result on two dimensions. For example, on Dim-3, in the Book-1 result, 'dialogue-based' was at the plus area of the axis and 'passage-based' at the minus area, while in the Book-3 result (the present one), 'passage-based' was at the plus area of the axis and 'dialogue-based' at the minus area. In the same 
manner, on Dim 6 in the Book-1 result, 'concise' was at the plus area of the axis and 'redundant' at the minus area, while in the Book-3 result, 'redundant' was at the plus area and 'concise' at the minus area. Thus, it could be concluded that the Book-3 data was perfectly explained under the same framework as that of the Book-1 result, which might suggest the accuracy and stability of CA.

The results of the present CA were graphically represented by two methods, (1) two-dimensional coordinate representation covering only two major dimensions, Dim 1 and Dim 2, and (2) cluster-analysis-based dendrogram covering all the features of the sixteen dimensions. These representations revealed that on the two-dimensional coordinate representation, only two textbooks, Sunshine-3 and Inoue-p3, were separated as distinctively different from the other fifteen textbooks by the two features, i.e., difficulty / easiness (Dim 1) and naturalness / artificialness (Dim 2), while on the dendrogram covering all of the sixteen features or categories specified, three textbooks, Inouep3, Sunshine-3 and Mombusho-p3 were separated as distinctively different from the others. These facts could suggest that all categories considered, two textbooks, Inoue-p3 and Mombusho-p3 should be included in the forerunner group represented by the current textbook, Sunshine-3.

\section{Limitations and future research}

Concerning the limitations of the present study and the directions for the future research, three points must be underlined.

First, the results of the present analysis proved that the CA with eighteen thirdyear EFL textbook variants was not successful enough in specifying their distinctive features, discriminating the similarities and differences among them, which made it necessary to change the CA model from eighteen variants to seventeen variants. Clearly, this is not an ideal procedure as expected. To solve this problem, attempts had to be made to develop a new method, technique or model for the CA with a large corpus.

Second, the present CA model, which is focused on the individual-year book rather than the one-to-five-year books of a textbook, did not succeed in describing and explaining the features of the whole books of a textbook. A new, innovative attempt must be made to overcome this limitation by developing a new CA model or procedure for processing a large corpora covering eighteen first-to-five-year EFL textbooks.

Finally, a methodological comment must be made on the statistic technique employed in the present CA, in particular, about the cross-tabulation frequency table of the nominal variants. In making an across-textbook tabulation table for CA, usually, as in the present study, top 100 most frequently used words are picked up for each variant (textbook) and their wordlists are combined to form an integrated cross-textbook word-frequency table. This system seems to work well generally when the number of variants are not so large, but when the number of the variants are larger than ten as in the present CA where there were 
seventeen variants and their similarity was not originally expected, the analysis results tend to be so instable that the interpretation of the dimensions computed seems to become rather difficult. This was exactly what happened in the present analysis, which made the interpretation of the result and naming of the dimensions extremely difficult. The present authors believe that there should be some efforts to be made to reconsider and re-examine these facts and develop some new alternative techniques.

\section{References}

Clausen, S. E. (1998). Applied correspondence analysis: An introduction. California: Sage Publications.

Fukui, M. \& Watanabe, K. (2019). Tekisuto CR bunnseki no gosuu chouseihou to tango no sentaku: Senyou puroguramu no kaihatu [Number adjustment and selection of words for textual analyses with correspondence analysis: Development of a special program]. ICTATLL, Japan Workshop, Prompt report, March 13, 2019.

Honda, R., Asai, T., Watanabe, K., \& Ozasa, T. (2018). A Correspondence Analysis of Seventeen Japanese Historical Third-Year English-as-a-Foreign-Language Textbooks. International Journal of Learning, Teaching and Educational Research, 17(11), 102-134. doi: 10. 26803/ijlter. 17. 11. 8

Honda, R., Watanabe, K., \& Ozasa, T. (2017). A correspondence analysis of nine Japanese historical English-as-a-foreign-language textbooks. International Journal of Learning, Teaching and Educational Research, 16(10), 100-113. doi: 10. 26803/ijlter. 16. 10.8

Hosaka, Y., Abe, N., Uenishi, K., \& Ozasa, T. (2008). To-infinitive in Japan's EFL textbooks: A diachronic comparison. Proceedings of $4^{\text {th }}$ International ICTATLL (ICT in the Analysis, Teaching and Learning of Languages) Workshop, University of Colombo, Sri Lanka, September, 2008, 1-5.

Hosaka, Y., Erikawa, H., Miura, S., \& Ranjan, C. K. (2008). Verbals in Japan's first-year EFL textbooks: A diachronic quantitative comparison. In G. R. S. Weir \& T. Ozasa (Eds.), Studies in language and textbook analysis. (pp. 143-148). Glasgow, Scotland: University of Strathclyde Publishing.

Kawamura, K., Umamoto, T., Matsuoka, H., \& Ozasa, T. (2017). Meiji-Showaki no eigo kyokasho no ri-dabiriti bunseki: Jogakko kyokasho o chushin tosite [Readability of four English textbooks used from the Meiji to Showa Era in Japan: Focusing on girls' middle school textbooks]. Journal of ICTATLL (ICT in the Analysis, Teaching and Learning of Languages) Japan, 4, 71 - 85.

Kawamura, K., Umamoto, T., \& Ozasa, T. (2016). Meijiki-gendai no eigo kyokasho 9shu no ri-dabiriti bunseki: Ozasa-Fukui Year Level, Ver. 3.4.2nhnc1-5 niyoru bunseki [Readability of nine English textbooks used from the Meiji Era to the present day in Japan: An analysis with the use of Ozasa-Fukui Year Level, Ver. 3.4.2nhnc1-5]. Journal of ICTATLL (ICT in the Analysis, Teaching and Learning of Languages) Japan, $3,85-99$.

Nakamura, T., \& Ozasa, T. (2007). Diachronic and synchronic analysis of English textbooks: With a focus on the gender awareness. Proceedings of the 12th Conference of Pan-Pacific Association of Applied Linguistics, Pataya, Thailand, 19-21, December, 2007, 126-129.

Ozasa, T. (2003). Meiji, Taisho, Showa-shoki no eigo kyokasho no keiryouteki bunseki [A quantitative analysis of Japanese historical EFL textbooks published from the 
Meiji Era (1868-1912), the Taisho Era (1912-1926) and the early Showa Era (19261945)]. Research report of the Japanese Scientific Research Grant, 2000 - 2002, Basic Research (C) (1) 12680269.

Ozasa, T. (2005). Meiji, Taisho, Showa-shoki no eigo kyokasho no keiryouteki bunseki [A quantitative analysis of Japanese historical EFL textbooks published from the Meiji Era (1868-1912), the Taisho Era (1912-1926) and the early Showa Era (19261945)]. Research report of the Japanese Scientific Research Grant, 2003 - 2004, Basic Research (C) (1) 15520358.

Ozasa, T., \& Erikawa, H. (Eds.). (2004). Eigo kyokasho no rekishiteki kenkyu [A historical study of [Japanese] English textbooks]. Tokyo, Japan: Jiyusha.

Ozasa, T., Fukui, M., \& Watanabe, K. (2015). Development of a readability index attuned to the new English course of study of Japan (3): Development of Ozasa-Fukui Year Level, Ver. 3.4.2nhnc1-5. In Pixel (Ed.), Conference Proceedings, $8^{\text {th }}$ International Conference of ICT for Language Learning, Florence, Italy, 12-13 November, 2015, 349-354.

Ozasa, T., Kawamura, K., Umamoto, T., \& Matsuoka, H. (2018). 1900-1908nen shuppan no shogakko eigo kyokasho 4shu to genko chugakko kyokasho no taiobunseki [Correspondence analysis of four Japanese primary school EFL textbooks published during 1900-1908 and a current junior high school textbook]. Journal of ICTATLL (ICT in the Analysis, Teaching and Learning of Languages) Japan, 5, 57 - 68.

Ozasa, T., \& Nakamura, Y. (2001). Meiji, Taisho, Showa shoki no eigo kyokasho nikansuru kenkyu: Shitsuteki bunseki to kaidai [A Study of [Japanese] historical English textbooks published in the Meiji, Taisho and Showa Era: A qualitative analysis and explanatory notes]. Hiroshima, Japan: Keisuisha.

Ozasa, T., Umamoto, T., Matsuoka, H., \& Motooka, N. (2008). Vocabulary of the firstyear EFL textbooks of Japan: A diachronic quantitative comparison. In G. R. S. Weir \& T. Ozasa (Eds.), Studies in language and textbook analysis. (pp. 149-155). Glasgow, Scotland: University of Strathclyde Publishing.

Ozasa, T., Watanabe, K., \& Fukui, M. (2016). Development of a readability index attuned to the new English course of study of Japan (4): Development of Ozasa-Fukui Year Level, Ver. 3.5nhnc1-6. Conference Proceedings, ICSSB (International Conference on Social Sciences and Business), Tokyo, Japan, August 25 - 27, 2016, 385394.

Sakamoto, M., Watanabe, K., \& Ozasa, T. (2017). A Correspondence analysis of five Japanese historical English-as-a-foreign-language textbooks. Conference Proceedings of ICSSB (International Conference on Social Science and Business), Okinawa, Japan, July 25 - 27, 2017, 132-144.

Tono, Y. (2000). A Corpus-based analysis of interlanguage development: Analysing partof-speech tag sequences of EFL learner corpora. In B. LewandowskaTomaszczyk, \& P. J. Melia (Eds.), Proceedings of PALC' 99: Practical Applications in Language Corpora, University of Lodz, Poland, 15-18 April, 1999 (pp. 323-340).

Watanabe, K., Asai, T., \& Ozasa, T. (2017). A correspondence analysis of five Japanese historical English-as-a-foreign-language textbooks. Conference Proceedings, ICEPL (International Conference on Education, Psychology, and Learning), Sapporo, Japan, August 23-25, 2017, 61-73.

Weir, G. R. S., \& Ozasa, T. (2007). Estimating naturalness in Japanese English textbooks. Proceedings of the 12th Conference of Pan-Pacific Association of Applied Linguistics, Pattaya, Thailand, 19-21, December, 2007, 130-133.

Weir, G. R. S., \& Ozasa, T. (Eds.). (2007). Texts, textbooks and readability. Glasgow, Scotland: University of Strathclyde Publishing. 
Weir, G. R. S., \& Ozasa, T. (2008). Multiword vocabulary in Japanese ESL texts.

Proceedings of the 13th Conference of Pan-Pacific Association of Applied Linguistics, University of Hawaii, U.S.A., 20-22 August, 2008, 63-66.

Weir, G. R. S., \& Ozasa, T. (Eds.). (2008). Studies in language and textbooks analysis. Glasgow, Scotland: University of Strathclyde Publishing.

Weir, G. R. S., \& Ozasa, T. (2009). Verb form usage in Japanese EFL texts. Proceedings of the 14th Conference of Pan-Pacific Association of Applied Linguistics, Kyoto, Japan, 31 July - 2 ${ }^{\text {nd }}$ August, 2009, 101-104.

Weir, G. R. S., \& Ozasa, T. (2010). Learning from analysis of Japanese EFL texts. Educational Perspectives (Journal of the College of Education, University of Hawaii at Manoa), 43, 1 \& 2, 56-66. 